\title{
Review Article \\ On-Site Surface Functionalization for Titanium Dental Implant with Nanotopography: Review and Outlook
}

\author{
Byung Gyu Kim, ${ }^{1}$ Seog-Jin Seo,, Jung-Hwan Lee, ${ }^{1,2}$ and Hae-Won Kim ${ }^{2,3,4}$ \\ ${ }^{1}$ NY ByungChun Dental Clinic, Aunaesundae-gil 54, Cheonan 31254, Republic of Korea \\ ${ }^{2}$ Institute of Tissue Regeneration Engineering (ITREN), Dankook University, Daeda-ro 119, Cheonan 31116, Republic of Korea \\ ${ }^{3}$ Department of Nanobiomedical Science \& BK21 PLUS NBM Global Research Center for Regenerative Medicine, \\ Dankook University, Daeda-ro 119, Cheonan 31116, Republic of Korea \\ ${ }^{4}$ Department of Biomaterials Science, College of Dentistry, Dankook University, Dande-ro 119, Cheonan 31116, Republic of Korea
}

Correspondence should be addressed to Jung-Hwan Lee; ducious@gmail.com

Received 22 April 2016; Accepted 4 September 2016

Academic Editor: Régis Guegan

Copyright (c) 2016 Byung Gyu Kim et al. This is an open access article distributed under the Creative Commons Attribution License, which permits unrestricted use, distribution, and reproduction in any medium, provided the original work is properly cited.

Titanium (Ti) has been the first choice of material for dental implant due to bonding ability to natural bone and great biocompatibility. Various types of surface roughness modification in nanoscale have been made as promising strategy for accelerating osseointegration of Ti dental implant. To have synergetic effect with nanotopography oriented favors in cell attachment, on-site surface functionalization with reproducibility of nanotopography is introduced as next strategy to further enhance cellular bioactivity. Extensive research has been conducted to investigate the potential of nanotopography preserved on-site surface functionalization for Ti dental implant. This review will discuss nonthermal atmospheric pressure plasma, ultraviolet, and low level of laser therapy on Ti dental implant with nanotopography as next generation of surface functionalization due to its abilities to induce superhydrophilicity or biofunctionality without change of nanotopography.

\section{Introduction}

Titanium (Ti) has long been used as an implant material in dentistry due to its remarkable corrosion resistance of its $\mathrm{Ti}$ oxide layer and powerful physical load [1]. In order to improve biological functions of Ti implants, various techniques of Ti surface modification such as surface roughness, chemistry, topography, and electrical charge have been suggested, focusing on the biological performance of Ti surface properties [2]. These surface modifications at the micrometer or nanometer scale have effectively promoted biological performance of Ti implants such as cell growth and functions in vitro $[3,4]$ and osseointegration in vivo [5] when compared to untreated surfaces.

Recently, nanostructures of Ti implant surface have been shown to further mimic the natural bone structure, possibly considering the biological pertinence of nanotopography for osteoblast or stem cells to attach, proliferate, or differentiate to achieve osseointegration [6-8]. For this, various methods for surface nanotopography of Ti implants have been developed at the nanoscale, such as lithography [9], crystal deposition [10], acid etching [11], sandblasting [12], and their combinations $[13,14]$. Although these techniques physically or chemically are known to obtain optimal surface characteristics for accelerating osseointegration in the field of basic research, reactivating surface functionality on aged $\mathrm{Ti}$ implants may be issued in a clinical setting, probably leading to clinical failure in dental implants [15]. In addition, rough $\mathrm{Ti}$ surfaces are generally hydrophobic and have high tendency to bacteria attachment, which can cause high risks of peri-implantitis, consequently failing in dental implant cases $[16,17]$.

To overcome these, several nanotopography preserved on-site surface functionalizations for Ti implants have been suggested: nonthermal atmospheric pressure plasma, ultraviolet, and laser [18-21]. On-site surface functionalizations are one of the alternative strategies to existing surface modifications and can maintain nanotopographical surfaces of $\mathrm{Ti}$ implants due to the chair-side applicability, sustainability of 


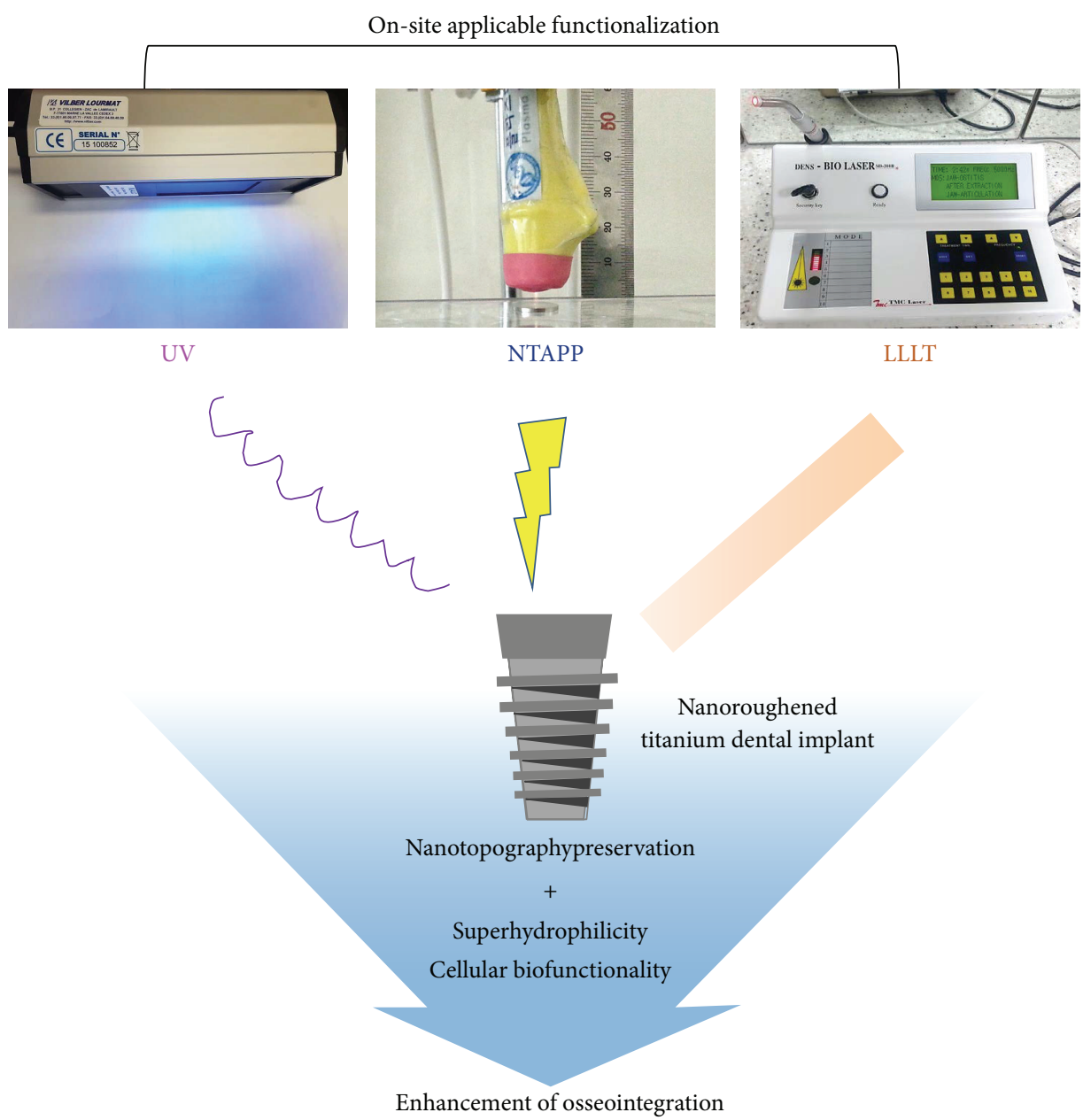

FIGURE 1: On-site applicable and nanotopography preserved surface functionalization methods for Ti dental implant (UV, ultraviolet, NTAPP, nonthermal atmospheric pressure plasma, and LLLT, low level of laser therapy).

functionalized effects with their enhanced biological potential before implant surgery, and no-damaged surface roughness. This review covers and suggests possible on-site applicable surface functionalization methods for Ti dental implant (Figure 1).

\section{Nonthermal Atmospheric Pressure Plasma}

Plasmas are defined as "the 4th state of matter" and contain a large amount of highly reactive species including ions, free radicals, electrons, and electronically excited atom or neutrals [22]. When plasma is produced at atmospheric pressure and the temperature of excited gas is at $300 \mathrm{~K}$ around, nonthermal atmospheric pressure plasma (NTAPP) is produced and can be treated onto the surface of implants for functionalization by the controllable plasma reactive species [23].

Once being exposed to plasma, the surface properties of the biomaterials can be functionalized as a result of the "bombing" of these reactive species. NTAPP treatment on biomaterials has been used to improve surface properties and to induce decontamination [24]. Because NTAPP has several advantages, such as induction of an increase in surface energy with very short treatment time, being on-site applicable, preservation of nanotopography, relatively low price, and simple fabrication process compared to vacuum-based plasma [25], NTAPP treatment has gained attention for Ti dental implant functionalization with preserving nanotopography $[26,27]$. For instance, cell size of human osteoblastic cells adherent on argon-based-NTAPP-pretreated specimen was significantly larger than that on nontreated surfaces irrespective of surface topography, which supported spreading of osteoblastic cells and thereby could accelerate osseointegration [28]. In terms of osteoblastic-differentiated gene expression, Nitrogen or air-based NTAPP-treated $\mathrm{TiO}_{2}$ nanotubes exhibited higher osteogenic gene expressions level depending on the working gas without changes in nanotopographical morphology [29].

In an additional example, nitrogen-based NTAPP-treated sandblasting with large-grit sand particles and acid etching subsequently (SLA) treated dental implant, which is clinically accepted golden Ti surface with microtopography/nanotopography, improved cellular activity on treated surface as well as wettability. Preosteoblast attachment and its proliferation were increasingly observed on NTAPP-treated SLA dental 
implant due to increased wettability and decreased hydrocarbon contamination without topographical changes. Both studies opened the possibility of application for enhancing osseointegration of Ti dental implants in a way of nanotopography preserved state [27].

Additionally, NTAPP treatment can be applied for increasing success of Ti dental implant by increasing soft tissue healing and preventing peri-implantitis. Human keratinocytes and HGFs on NTAPP-treated Ti implants showed an increase in proliferation or migration, which is beneficial for increasing implant-soft tissue sealing [30]. Additionally, direct NTAPP treatment to adherent human gingival fibroblasts (HGFs) on machined Ti substrates revealed possible application for gingival tissue healing due to an increase in intracellular reactive oxygen species (ROS) and upregulation of three migration-related genes (EGFR, PAK1, and MAPK1) and EGFR activation [21]. Recently, NTAPP treatment onto Ti dental implants has shown antifouling effects to oral bacteria related to peri-implantitis. Roughened Ti surfaces including SLA have hydrophobic characteristics, leading to inducing bacteria attachment and consequently failing in implants. Investigation of the effects by NTAPP treatment on the Ti dental implant surfaces for the inhibition of two common pathogens (Streptococcus mutans and Staphylococcus aureus) was carried out and showed that there was a reduction of adherent bacteria and the significant change in morphology of bacteria. These results were attributed to increased hydrophilicity on the surface of NTAPP-treated Ti implants [20].

NTAPP has been applied for enhancing success of dental implant restoration with sustaining topographical characteristics in the nanoscale, but there are still limitations in terms of clinical application. NTAPP-produced radicals, which play a major role to modify surface characteristics, are easily influenced by even tiny change in humidity and gas composition, which do not guarantee reproducibility of NTAPP equipment in clinical situation. Moreover, safety issues from exposed radicals to air could be raised because they can react with sensitive normal tissues such as eyes. With regard to prevention of possible exposure to eye and other exposed tissues, high volume suction should be accompanied to evacuate any radical plume created during plasma production, and protective eyewear should be worn for operator, patients, and other assistant people. In terms of osseointegration by NTAPP treatment, in vivo or preclinical study has not been performed to show possibility of clinical application. For overcoming above limitations, accurate NTAPP machine with controlled working gas injector is needed to set up reproducibility of NTAPP-induced radical, and in vivo study using rabbit or adult dog to investigate osseointegration is necessary.

\section{Ultraviolet}

Ultraviolet (UV) photofunctionalization to Ti implants can alter physicochemical properties of the surface, such as generation of superhydrophilicity and pollutant-degrading, antifogging, antibacterial, and stain-proofing properties [31, 32]. Enhancement of biologic capabilities without topographical change was able to be observed on the surface of UV-treated $\mathrm{TiO}_{2}$ semiconductor [33].

In terms of biologic ability from UV treatment, bone morphogenesis around UV-treated Ti implants was distinctly improved compared with untreated control implants, leading to rapid and complete establishment of osseointegration with nearly $100 \%$ bone-to-implant contact in an animal model, as opposed to less than $55 \%$ for untreated implants [33]. A series of in vitro studies demonstrated considerable enhancement of attachment, proliferation, differentiation, and subsequent functional cascades of osteogenic lineages from animals and humans after UV treatment [34]. Basically, UV treatment is known to convert Ti surfaces from hydrophobic to superhydrophilic due to removal of unavoidably contaminated hydrocarbons [35]. In this model, UV treatment creates more expression of $\mathrm{Ti}^{4+}$ sites on outer Ti surface, which is favorable for dissociative water or adhesive protein adsorption. In addition, UV-treated Ti surfaces manifest a unique electrostatic status and thereby act as direct cell attractants without the help of ionic and organic bridges, which induces a novel physicochemical functionality to $\mathrm{Ti}$ [36]. Other advantages of UV treatment are simplicity of treatment devices and treatment methods, low cost, portability, and diverse applicability for all types of Ti alloys (Ti6Al4V and Ti-Ag) and Ti surfaces tested such as machined surfaces, SLA, and Ti nanotube formed and micro-arc oxidation surface [37-40].

When SLA surface, most promising Ti surface among commercially available dental implants, including nanopits and micropits was treated by UV, it induced superhydrophilicity, tailored mesenchymal stem cells into osteoblastic lineage, and accelerated attachment, proliferation, and migration without change of surface architectures [36, 41]. The attachment, spreading, settling, proliferation, and alkaline phosphate activity of bone marrow-derived osteoblasts were promoted on Ti or apatite-coated Ti after photofunctionalization compared to nontreated counterpart, which induced high bone-implant contact to reduce peri-implant stress [42]. Most of the upregulated biofuctionalities by UV photofunctionalization were revealed due to an increase in protein adsorption such as fibrinogen and other attachable proteins [43].

UV-mediated photofunctionalization is effective to enhance bone tissue formation on the Ti mesh [44]. In addition, UV photofunctionalization accelerated and enhanced levels of osseointegration and overcame impaired osseointegration even in type 2 diabetes using a rat model [45]. In a clinical study, implant stability and osseointegration speed of immediately loaded implants were increased through UV treatment. Additionally, UV irradiation reduced the attachment and biofilm formation of wound pathogens on various topographical Ti surfaces [46]. The mechanism might involve superhydrophilicity and carbon elimination on the surface. These data suggest that UV photofunctionalization can be a novel, effective measurement to improve implant therapy for mal-regenerative patients in the dental and orthopedic fields. Besides, UV treatment is able to overcome time-related degrading bioactivity of $\mathrm{Ti}$, which means UV on-site treatment on Ti has a potential to restore the possible adverse 
effects of Ti aging in terms of osseointegration [35, 47]. From manufacturer, UV-pretreated dental Ti including SLAtreated $\mathrm{Ti}$ has been distributed in market with being immersed into $\mathrm{CaCl}_{2}$ and $\mathrm{NaCl}_{2}$ solution to avoid Ti aging. However, future research will be needed to validate these promising aspects using in vivo or clinical studies in terms of enhanced osteoconductivity [34].

Even though UV treatment has been applied for enhancing success of dental implant restoration without change of topographical characteristics, there are still limitations in clinical applications. UV treatment requires relatively long exposure time compared to NTAPP and thereby cannot apply for on-site treatment in clinical situation. Whether specific type of dental implants is set to be exposed to UV treatment according to the anatomical data from digital images, they can be changed into another type depending on the bone width, height, and density on surgery day for Ti implantation. Moreover, safety issues from photofunctionalized Ti surface could be raised because the surface can react with stem cells and may activate various biological signaling in an unexpected way, which can adversely affect osseointegration. In addition, interplay with osteoclast, macrophage, and other important cell types for osseointegration is still under investigation. Even though, in terms of osseointegration by UV treatment, in vitro, in vivo, or preclinical study has been performed to show possibility of clinical application, biological mechanisms of cells on photofunctionalized Ti surface and safety issues are still remaining under consideration. For overcoming above limitations, UV machine with high performance is needed to be developed for decreasing treatment time for on-site application of nanotopographical Ti implants and more in vitro studies for revealing cellular mechanisms and long term in vivo or clinical studies are necessary to investigate promising and safety usages of UV treatment for successful osseointegration.

\section{Low-Level Laser Therapy}

The term "laser," which is an abbreviation for "Light Amplification by the Stimulated Emission of Radiation" was firstly applied in dentistry by Maiman in 1960 and has been used for hard and soft tissue applications especially for removing or cutting certain part of them [48]. For example, in hard tissue application, the laser is used for cutting bone, bleaching, restorative removal, and cavity preparation as well as caries prevention and dentinal hypersensitivity, whereas soft tissue application includes removal of soft tissue to uncover impacted or partially erupted tooth or photostimulate herpetic lesion or malignancies [49]. In the United States, the use of lasers was first approved by the Food and Drug Administration in around 1990s on the gingival soft tissue, and use on hard tissue such as teeth or the bone of the mandible gained approval in 1996 [50]. In the last decade, there has been an explosion of research investigations in laser application on Ti implant surface due to many advantages of laser such as great specificity, on-site applicability with currently used laser device, and cost-efficiency [51].

Several variants of dental lasers are in use with different wavelengths and these mean they are better optimized for different applications. There are two types: on one hand there are hard lasers such as Er:YAG laser and Er,Cr:YSGG laser, whereas, on the other hand as cold or soft laser, there are carbon dioxide lasers, Nd:YAG laser, and light-emitting diodes, which are compact, low-cost devices, and they are termed as low-level laser therapy (LLLT) or "biostimulation" [52]. Hard lasers and other soft lasers except LLLT have limitation in applying for nanotopography preserved on-site surface functionalization for $\mathrm{Ti}$ dental implants due to surface roughness changes as well as high costs [53]. Even though above laser-treated surfaces induced an increase in biologic response with bone marrow stem cells and many types of osteoblastic lineages and may lead to improved bone-toimplant contact due to high surface energy and the macrostructures/microstructures of Ti implant $[54,55]$, topographical characteristics could not be preserved in nanoscale. Therefore, LLLT pretreatment on Ti dental implants and its effects for osseointegration will be discussed in this section.

LLLT including diode laser, gallium-aluminum-arsenide (GaAlAs) diode, and helium-neon laser have been introduced to have biostimulating potentials on Ti without surface morphology changes, therefore accelerating the healing process [56]. The area of effect is larger than that in the high-energy hard laser ones and therefore the heat is dispersed well, which may not result in alterations of the surface topography in the nanoscale. Therefore, most studies with LLLT in implantology were focused on an acceleration of osseointegration on $\mathrm{Ti}$ implants. There exist many articles analyzing the potential effects of these therapies on the osseointegration of Ti dental implants. The results in the group irradiated with LLLT on Ti implants reported beneficial effects from the microscopic point of view: increased bone-implant contact, better bonding ability to natural bone, greater percentage of calcium, phosphates, and hydroxyapatite composition in healing site, an increase in osteoblast differentiation related gene expression such as osteoprotegerin, receptor activator of nuclear factor kappa-B ligand, and no effect on bone resorption [5762]. Above in vitro data suggest that LLLT irradiated Ti has a potential to induce faster bone maturation, improves bone healing, and increases the cellular activity, including proliferation and attachment, in Ti material with increased activity of alkaline phosphatase compared to the control group [62].

Besides, the use of LLLT can be applied for treating chronic periodontitis, hypersensitivity, oral mucositis, and orthodontic pain as well as decreasing infections around dental implants [63-66].

Even though LLLT treatment has been applied for dental implant restoration without change of topographical characteristics, there are still limitations for clinical application. LLLT treatment also requires more than 24 hours, which is relatively long exposure time compared to NTAPP and cannot be applied for on-site treatment in clinical situation. Even though a specific type of dental implant is exposed to LLLT treatment in clinic, dimensions of Ti implant can be changed. Although optimized time of LLLT did not induce changes in topology, there is still a chance of alteration in the nanoscale when treatment time is increasing. In addition, in terms of rationale to link LLLT-treated $\mathrm{Ti}$ and osteoblastic 
TABLE 1: Advantages and disadvantages of on-site surface functionalization for Ti dental implant.

\begin{tabular}{|c|c|c|}
\hline & Advantages & Disadvantages \\
\hline \multirow{7}{*}{ NTAPP } & Superhydrophilicity & Safety issues \\
\hline & Preservation of microtopography/nanotopography & Lack of in vivo and clinical data for help of osseointegration \\
\hline & Short treatment time (less than 1 minute) & Lack of safety data \\
\hline & Decontamination effect & \\
\hline & Antifouling effect & \\
\hline & Increase of periodontal tissue healing and sealing with implant & \\
\hline & A lot of in vitro data & \\
\hline \multirow{6}{*}{ UV } & $\begin{array}{l}\text { Hydrophilicity, superhydrophilicity depending on the } \\
\text { treatment time }\end{array}$ & Long treatment time (few hours) \\
\hline & Preservation of microtopography/nanotopography & Lack of clinical data as on-site treatment method \\
\hline & Relatively good clinical safety & Possible damage to soft tissue \\
\hline & Decontamination effect & \\
\hline & Antifouling effect & \\
\hline & A lot of in vitro and in vivo data & \\
\hline \multirow{3}{*}{ LLLT } & Hydrophilicity & Long treatment time (few hours) \\
\hline & Preservation of microtopography/nanotopography & Lack of data for help of osseointegration \\
\hline & Great clinical safety with safety instrument & Lack of cellular mechanism \\
\hline
\end{tabular}

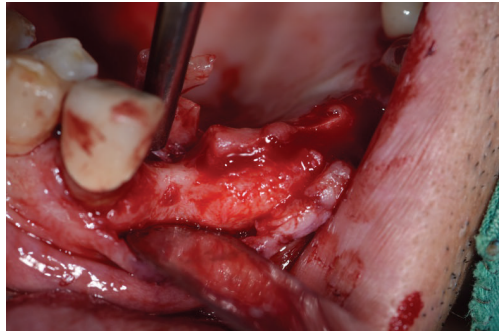

(a)

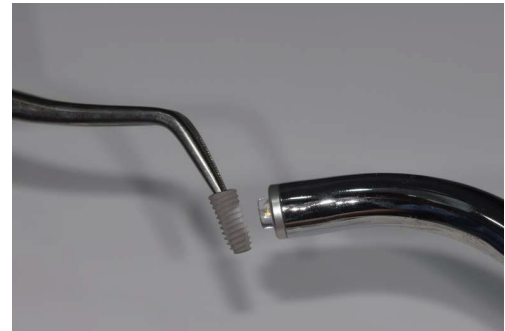

(b)

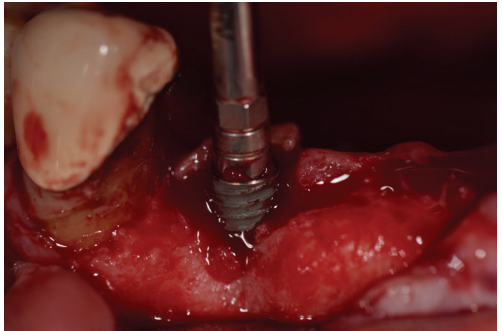

(c)

FIGURE 2: On-site dental titanium implant fixture functionalization method for clinical application. (a) Surgical preparation in missing tooth site before dental titanium fixture implantation with opening periodontal soft tissue from alveolar bone. (b) On-site functionalization treatment (i.e., LLLT) on dental titanium fixture. (c) Dental titanium fixture implantation on alveolar bone.

lineage, there is insufficient proof at the moment. Safety issues from LLLT treatment also remain because certain precautions should be taken to ensure safety [49]. First and foremost risk factor is eye damage from laser to anyone such as operating doctor, assistants, and patient during procedure. It should be advised to wear protective eyewear for preventing potential eye damage. Additionally, accidental exposure to nontarget biomaterial or normal tissues such as surrounding tissue or finger of operator can be prevented by the use of protective ware and limiting access to the equipment and operating environment to minimize the unwanted effects from reflective laser. In terms of osseointegration by LLLT treatment, more in vitro, in vivo, or preclinical studies are necessary to show possibility of clinical application and to optimize protocol (power, time, and type) to induce increase of biological activity of osteoblastic lineages without topographical changes because only few in vitro and animal studies have shown a positive effect on osseointegration of $\mathrm{Ti}$ implants.

\section{Concluding Remarks}

Table 1 shows advantages and disadvantages of on-site surface functionalization method for Ti dental implant. Among three potential nanotopography preserved functionalizing methods, NTAPP seems to be the best due to short treatment time and high efficiency to induce superhydrophilicity. UV treatment mostly used in clinics is also convenient except long period for treatment, which is the reason why UV treatment is only performed in manufacturer. With the drawback in terms of long treatment time, LLLT treatment using various types of lasers has the longest history and may be acceptable due to its early introduction to dental application for modifying surface characteristics on $\mathrm{Ti}$ surface. However, it is still unclear to understand biological mechanisms to link the bridge between LLLT-treated Ti and cells as well as clinical study.

On-site surface functionalization is considered as a promising strategy to enhance osseointegration due to synergetic advantages from reproducibility of topography and surface bioactivity from on-site treatment (Figure 2). In the future, 
for the immune or osteoinductive-suppressed patients who suffer from complications of drug use and systemic diseases such as diabetes mellitus and other genetic disorders, the promising biological effects from on-site surface functionalized Ti dental implant with nanotopography can be applied for enhancing success of osseointegration of Ti dental implant. However, in vivo and preclinical studies are insufficient to show promising effects for clinical application. Additionally, bacterial resistance effect on roughened $\mathrm{Ti}$ in the nanoscale from surface functionalization remains still under investigation. Further preclinical and clinical studies in terms of osseointegration and bacterial resistance are needed.

\section{Disclosure}

Byung Gyu Kim and Seog-Jin Seo are co-first authors.

\section{Competing Interests}

The authors declare that there are no competing interests regarding the publication of this article.

\section{Acknowledgments}

This research was supported by Basic Science Research Program through the National Research Foundation of Korea (NRF) funded by the Ministry of Education (Grant no. 2009-0093829) and Research Fellowship Program (NRF2013R1A1A2062694).

\section{References}

[1] P.-I. Branemark, "Osseointegration and its experimental background," The Journal of Prosthetic Dentistry, vol. 50, no. 3, pp. 399-410, 1983.

[2] A. Jemat, M. J. Ghazali, M. Razali, and Y. Otsuka, "Surface modifications and their effects on titanium dental implants," BioMed Research International, vol. 2015, Article ID 791725, 11 pages, 2015.

[3] S.-M. Bang, H.-J. Moon, Y.-D. Kwon, J.-Y. Yoo, A. Pae, and I. K. Kwon, "Osteoblastic and osteoclastic differentiation on SLA and hydrophilic modified SLA titanium surfaces," Clinical Oral Implants Research, vol. 25, no. 7, pp. 831-837, 2014.

[4] U. Hempel, T. Hefti, P. Dieter, and F. Schlottig, "Response of human bone marrow stromal cells, MG-63, and SaOS-2 to titanium-based dental implant surfaces with different topography and surface energy," Clinical Oral Implants Research, vol. 24, no. 2, pp. 174-182, 2013.

[5] L. Salou, A. Hoornaert, G. Louarn, and P. Layrolle, "Enhanced osseointegration of titanium implants with nanostructured surfaces: an experimental study in rabbits," Acta Biomaterialia, vol. 11, no. 1, pp. 494-502, 2015.

[6] L. E. McNamara, T. Sjöström, K. Seunarine, R. D. Meek, B. $\mathrm{Su}$, and M. J. Dalby, "Investigation of the limits of nanoscale filopodial interactions," Journal of Tissue Engineering, vol. 5, 2014.

[7] M. M. McCafferty, G. A. Burke, and B. J. Meenan, "Calcium phosphate thin films enhance the response of human mesenchymal stem cells to nanostructured titanium surfaces," Journal of Tissue Engineering, vol. 5, 2014.
[8] X. Wang, O. Zakaria, M. Madi, and S. Kasugai, "Vertical osteoconductivity of sputtered hydroxyapatite-coated mini titanium implants after dura mater elevation: rabbit calvarial model," Journal of Tissue Engineering, vol. 6, 2015.

[9] M. Domanski, R. Luttge, E. Lamers et al., "Submicron-patterning of bulk titanium by nanoimprint lithography and reactive ion etching," Nanotechnology, vol. 23, no. 6, Article ID 65306, 2012.

[10] C.-Y. Chien, T.-Y. Liu, W.-H. Kuo, M.-J. Wang, and W.-B. Tsai, "Dopamine-assisted immobilization of hydroxyapatite nanoparticles and RGD peptides to improve the osteoconductivity of titanium," Journal of Biomedical Materials Research Part A, vol. 101, no. 3, pp. 740-747, 2013.

[11] X. Lin, L. Zhou, S. Li, H. Lu, and X. Ding, "Behavior of acid etching on titanium: topography, hydrophility and hydrogen concentration," Biomedical Materials, vol. 9, no. 1, Article ID 15002, 2014.

[12] J. C. Balza, D. Zujur, L. Gil et al., "Sandblasting as a surface modification technique on titanium alloys for biomedical applications: abrasive particle behavior," IOP Conference Series: Materials Science and Engineering, vol. 45, Article ID 012004, 2013.

[13] D. Buser, S. F. M. Janner, J.-G. Wittneben, U. Brägger, C. A. Ramseier, and G. E. Salvi, "10-Year survival and success rates of 511 titanium implants with a sandblasted and acid-etched surface: a retrospective study in 303 partially edentulous patients," Clinical Implant Dentistry and Related Research, vol. 14, no. 6, pp. 839-851, 2012.

[14] M. A. Surmeneva, R. A. Surmenev, A. I. Tyurin et al., “Comparative study of the radio-frequency magnetron sputter deposited CaP films fabricated onto acid-etched or pulsed electron beamtreated titanium," Thin Solid Films, vol. 571, no. 1, pp. 218-224, 2014.

[15] A. Arifin, A. B. Sulong, N. Muhamad, J. Syarif, and M. I. Ramli, "Material processing of hydroxyapatite and titanium alloy (HA/Ti) composite as implant materials using powder metallurgy: a review," Materials \& Design, vol. 55, pp. 165-175, 2014.

[16] A. Almaguer-Flores, R. Olivares-Navarrete, M. Wieland, L. A. Ximénez-Fyvie, Z. Schwartz, and B. D. Boyan, "Influence of topography and hydrophilicity on initial oral biofilm formation on microstructured titanium surfaces in vitro," Clinical Oral Implants Research, vol. 23, no. 3, pp. 301-307, 2012.

[17] H. Y. Lin, Y. Liu, D. Wismeijer, W. Crielaard, and D. M. Deng, "Effects of oral implant surface roughness on bacterial biofilm formation and treatment efficacy," The International Journal of Oral \& Maxillofacial Implants, vol. 28, no. 5, pp. 1226-1231, 2013.

[18] I. Hauser-Gerspach, C. Mauth, T. Waltimo, J. Meyer, and S. Stübinger, "Effects of Er:YAG laser on bacteria associated with titanium surfaces and cellular response in vitro," Lasers in Medical Science, vol. 29, no. 4, pp. 1329-1337, 2014.

[19] T. Ogawa, "Ultraviolet photofunctionalization of titanium implants," International Journal of Oral \& Maxillofacial Implants, vol. 29, no. 1, pp. e95-e102, 2014.

[20] E.-M. Yoo, S.-H. Uhm, J.-S. Kwon et al., "The study on inhibition of planktonic bacterial growth by non-thermal atmospheric pressure plasma jet treated surfaces for dental application," Journal of Biomedical Nanotechnology, vol. 11, no. 2, pp. 334-341, 2015.

[21] J.-H. Lee, E.-H. Choi, K.-M. Kim, and K.-N. Kim, "Effect of non-thermal air atmospheric pressure plasma jet treatment on gingival wound healing," Journal of Physics D: Applied Physics, vol. 49, no. 7, Article ID 075402, 2016. 
[22] J. H. Lee, J. Y. Om, Y. H. Kim et al., "Selective killing effects of cold atmospheric pressure plasma with no induced dysfunction of epidermal growth factor receptor in oral squamous cell carcinoma," PLoS ONE, vol. 11, no. 2, Article ID e0150279, 2016.

[23] J.-H. Lee, Y.-H. Kim, E.-H. Choi, K.-M. Kim, and K.-N. Kim, "Air atmospheric-pressure plasma-jet treatment enhances the attachment of human gingival fibroblasts for early peri-implant soft tissue seals on titanium dental implant abutments," Acta Odontologica Scandinavica, vol. 73, no. 1, pp. 67-75, 2015.

[24] X. Pan, C. Chen, K. Zhu, and Z. Fan, "TiO 2 nanotubes infiltrated with nanoparticles for dye sensitized solar cells," Nanotechnology, vol. 22, no. 23, Article ID 235402, 2011.

[25] J.-H. Lee, J.-S. Kwon, J.-Y. Om et al., "Cell immobilization on polymer by air atmospheric pressure plasma jet treatment," Japanese Journal of Applied Physics, vol. 53, no. 8, Article ID 086202, 2014.

[26] J.-H. Lee, J.-S. Kwon, Y.-H. Kim, E.-H. Choi, K.-M. Kim, and K.-N. Kim, "The effects of enhancing the surface energy of a polystyrene plate by air atmospheric pressure plasma jet on early attachment of fibroblast under moving incubation," Thin Solid Films, vol. 547, pp. 99-105, 2013.

[27] E.-J. Lee, J.-S. Kwon, S.-H. Uhm et al., "The effects of nonthermal atmospheric pressure plasma jet on cellular activity at SLA-treated titanium surfaces," Current Applied Physics, vol. 13, supplement 1, pp. S36-S41, 2013.

[28] K. Duske, I. Koban, E. Kindel et al., "Atmospheric plasma enhances wettability and cell spreading on dental implant metals," Journal of Clinical Periodontology, vol. 39, no. 4, pp. 400-407, 2012.

[29] H. Y. Seo, J.-S. Kwon, Y.-R. Choi, K.-M. Kim, E. H. Choi, and K.-N. Kim, "Cellular attachment and differentiation on titania nanotubes exposed to air- or nitrogen-based non-thermal atmospheric pressure plasma," PLoS ONE, vol. 9, no. 11, Article ID el13477, 2014.

[30] J.-S. Kwon, Y. H. Kim, E. H. Choi, C.-K. Kim, K.-N. Kim, and K.M. Kim, "Non-thermal atmospheric pressure plasma increased mRNA expression of growth factors in human gingival fibroblasts," Clinical Oral Investigations, vol. 20, no. 7, pp. 1801-1808, 2016.

[31] N. Suketa, T. Sawase, H. Kitaura et al., "An antibacterial surface on dental implants, based on the photocatalytic bactericidal effect," Clinical Implant Dentistry and Related Research, vol. 7, no. 2, pp. 105-111, 2005.

[32] T. Nakashima, Y. Ohko, Y. Kubota, and A. Fujishima, "Photocatalytic decomposition of estrogens in aquatic environment by reciprocating immersion of $\mathrm{TiO}_{2}$-modified polytetrafluoroethylene mesh sheets," Journal of Photochemistry and Photobiology A: Chemistry, vol. 160, no. 1-2, pp. 115-120, 2003.

[33] H. Aita, N. Hori, M. Takeuchi et al., "The effect of ultraviolet functionalization of titanium on integration with bone," Biomaterials, vol. 30, no. 6, pp. 1015-1025, 2009.

[34] T. Ogawa, "Ultraviolet photofunctionalization of titanium implants," The International Journal of Oral \& Maxillofacial Implants, vol. 29, no. 1, pp. e95-e102, 2014.

[35] T. Suzuki, N. Hori, W. Att et al., "Ultraviolet treatment overcomes time-related degrading bioactivity of titanium," Tissue Engineering Part A, vol. 15, no. 12, pp. 3679-3688, 2009.

[36] H. Aita, W. Att, T. Ueno et al., "Ultraviolet light-mediated photofunctionalization of titanium to promote human mesenchymal stem cell migration, attachment, proliferation and differentiation," Acta Biomaterialia, vol. 5, no. 8, pp. 3247-3257, 2009.
[37] M. Lorenzetti, O. Dakischew, K. Trinkaus et al., "Enhanced osteogenesis on titanium implants by UVB photofunctionalization of hydrothermally grown $\mathrm{TiO}_{2}$ coatings," Journal of Biomaterials Applications, vol. 30, no. 1, pp. 71-84, 2015.

[38] H. Minamikawa, T. Ikeda, W. Att et al., "Photofunctionalization increases the bioactivity and osteoconductivity of the titanium alloy Ti6Al4V," Journal of Biomedical Materials Research Part A, vol. 102, no. 10, pp. 3618-3630, 2014.

[39] Y. Gao, Y. Liu, L. Zhou et al., "The Effects of Different Wavelength UV Photofunctionalization on Micro-Arc Oxidized Titanium," PLoS ONE, vol. 8, no. 7, Article ID e68086, 2013.

[40] T. Ikeda, Y. Hagiwara, M. Hirota et al., "Effect of photofunctionalization on fluoride-treated nanofeatured titanium," Journal of Biomaterials Applications, vol. 28, no. 8, pp. 1200-1212, 2014.

[41] T. Miyauchi, M. Yamada, A. Yamamoto et al., "The enhanced characteristics of osteoblast adhesion to photofunctionalized nanoscale $\mathrm{TiO}_{2}$ layers on biomaterials surfaces," Biomaterials, vol. 31, no. 14, pp. 3827-3839, 2010.

[42] M. Saita, T. Ikeda, M. Yamada, K. Kimoto, M. C.-I. Lee, and T. Ogawa, "UV photofunctionalization promotes nanobiomimetic apatite deposition on titanium," International Journal of Nanomedicine, vol. 11, pp. 223-234, 2016.

[43] J. Wu, L. Zhou, X. Ding, Y. Gao, and X. Liu, "Biological effect of ultraviolet photocatalysis on nanoscale titanium with a focus on physicochemical mechanism," Langmuir, vol. 31, no. 36, pp. 10037-10046, 2015.

[44] M. Hirota, T. Ikeda, M. Tabuchi, T. Iwai, I. Tohnai, and T. Ogawa, "Effect of ultraviolet-mediated photofunctionalization for bone formation around medical titanium mesh," Journal of Oral and Maxillofacial Surgery, vol. 72, no. 9, pp. 1691-1702, 2014.

[45] Y. Sugita, Y. Honda, I. Kato, K. Kubo, H. Maeda, and T. Ogawa, "Role of photofunctionalization in mitigating impaired osseointegration associated with type 2 diabetes in rats," International Journal of Oral \& Maxillofacial Implants, vol. 29, no. 6, pp. 12931300, 2014.

[46] Y. Yamada, M. Yamada, T. Ueda, and K. Sakurai, "Reduction of biofilm formation on titanium surface with ultraviolet-C preirradiation," Journal of Biomaterials Applications, vol. 29, no. 2, pp. 161-171, 2014.

[47] H. Minamikawa, W. Att, T. Ikeda, M. Hirota, and T. Ogawa, "Long-term progressive degradation of the biological capability of titanium," Materials, vol. 9, no. 2, p. 102, 2016.

[48] T. H. Maiman, "Stimulated optical radiation in Ruby," Nature, vol. 187, no. 4736, pp. 493-494, 1960.

[49] S. K. Verma, S. Maheshwari, R. K. Singh, and P. K. Chaudhari, "Laser in dentistry: an innovative tool in modern dental practice," National Journal of Maxillofacial Surgery, vol. 3, no. 2, pp. 124-132, 2012.

[50] J. D. Kretlow, S. Young, L. Klouda, M. Wong, and A. G. Mikos, "Injectable biomaterials for regenerating complex craniofacial tissues," Advanced Materials, vol. 21, no. 32-33, pp. 3368-3393, 2009.

[51] R. Wadhawan, G. Solanki, A. Bhandari, A. Rathi, and R. Dash, "Role of laser therapy in dentistry: a review," International Journal of Biomedical Research, vol. 5, no. 3, pp. 153-157, 2014.

[52] M. S. Kamel, A. Khosa, A. Tawse-Smith, and J. Leichter, “The use of laser therapy for dental implant surface decontamination: a narrative review of in vitro studies," Lasers in Medical Science, vol. 29, no. 6, pp. 1977-1985, 2014.

[53] V. Moraschini, L. A. D. C. Poubel, V. F. Ferreira, and E. D. S. P. Barboza, "Evaluation of survival and success rates of dental 
implants reported in longitudinal studies with a follow-up period of at least 10 years: a systematic review," International Journal of Oral and Maxillofacial Surgery, vol. 44, no. 3, pp. 377388, 2015.

[54] S. Allegrini Jr., M. Yoshimoto, M. B. Salles, and A. H. D. A. Bressiani, "Biologic response to titanium implants with lasertreated surfaces," The International Journal of Oral \& Maxillofacial Implants, vol. 29, no. 1, pp. 63-70, 2014.

[55] E. Mariscal-Muñoz, C. A. S. Costa, H. S. Tavares et al., "Osteoblast differentiation is enhanced by a nano-to-micro hybrid titanium surface created by Yb:YAG laser irradiation," Clinical Oral Investigations, vol. 20, no. 3, pp. 503-511, 2016.

[56] H. Wan, R. L. Williams, P. J. Doherty, and D. F. Williams, "A study of cell behaviour on the surfaces of multifilament materials," Journal of Materials Science: Materials in Medicine, vol. 8, no. 1, pp. 45-51, 1997.

[57] N. Jakse, M. Payer, S. Tangl, A. Berghold, R. Kirmeier, and M. Lorenzoni, "Influence of low-level laser treatment on bone regeneration and osseointegration of dental implants following sinus augmentation: an experimental study on sheep," Clinical Oral Implants Research, vol. 18, no. 4, pp. 517-524, 2007.

[58] F. V. Gomes, L. Mayer, F. P. Massotti et al., "Low-level laser therapy improves peri-implant bone formation: resonance frequency, electron microscopy, and stereology findings in a rabbit model," International Journal of Oral and Maxillofacial Surgery, vol. 44, no. 2, pp. 245-251, 2015.

[59] C. Boldrini, J. M. de Almeida, L. A. Fernandes et al., "Biomechanical effect of one session of low-level laser on the bonetitanium implant interface," Lasers in Medical Science, vol. 28, no. 1, pp. 349-352, 2013.

[60] M. Khadra, H. J. Rønold, S. P. Lyngstadaas, J. E. Ellingsen, and H. R. Haanæs, "Low-level laser therapy stimulates boneimplant interaction: an experimental study in rabbits," Clinical Oral Implants Research, vol. 15, no. 3, pp. 325-332, 2004.

[61] C. B. Lopes, A. L. B. Pinheiro, S. Sathaiah, N. S. Da Silva, and M. A. C. Salgado, "Infrared laser photobiomodulation $(\lambda 830 \mathrm{~nm})$ on bone tissue around dental implants: a Raman spectroscopy and scanning electronic microscopy study in rabbits," Photomedicine and Laser Surgery, vol. 25, no. 2, pp. 96-101, 2007.

[62] O. Dörtbudak, R. Haas, and G. Mailath-Pokorny, "Effect of lowpower laser irradiation on bony implant sites," Clinical Oral Implants Research, vol. 13, no. 3, pp. 288-292, 2002.

[63] C. M. Cobb, "Lasers in periodontics: a review of the literature," Journal of Periodontology, vol. 77, no. 4, pp. 545-564, 2006.

[64] A. Sculean, F. Schwarz, and J. Becker, "Anti-infective therapy with an Er:YAG laser: influence on peri-implant healing," Expert Review of Medical Devices, vol. 2, no. 3, pp. 267-276, 2005.

[65] F. Sgolastra, A. Petrucci, M. Severino, R. Gatto, and A. Monaco, "Lasers for the treatment of dentin hypersensitivity: a metaanalysis," Journal of Dental Research, vol. 92, no. 6, pp. 492-499, 2013.

[66] S. Oberoi, G. Zamperlini-Netto, J. Beyene, N. S. Treister, and L. Sung, "Effect of prophylactic low level laser therapy on oral mucositis: a systematic review and meta-analysis," PLoS ONE, vol. 9, no. 9, Article ID e107418, 2014. 

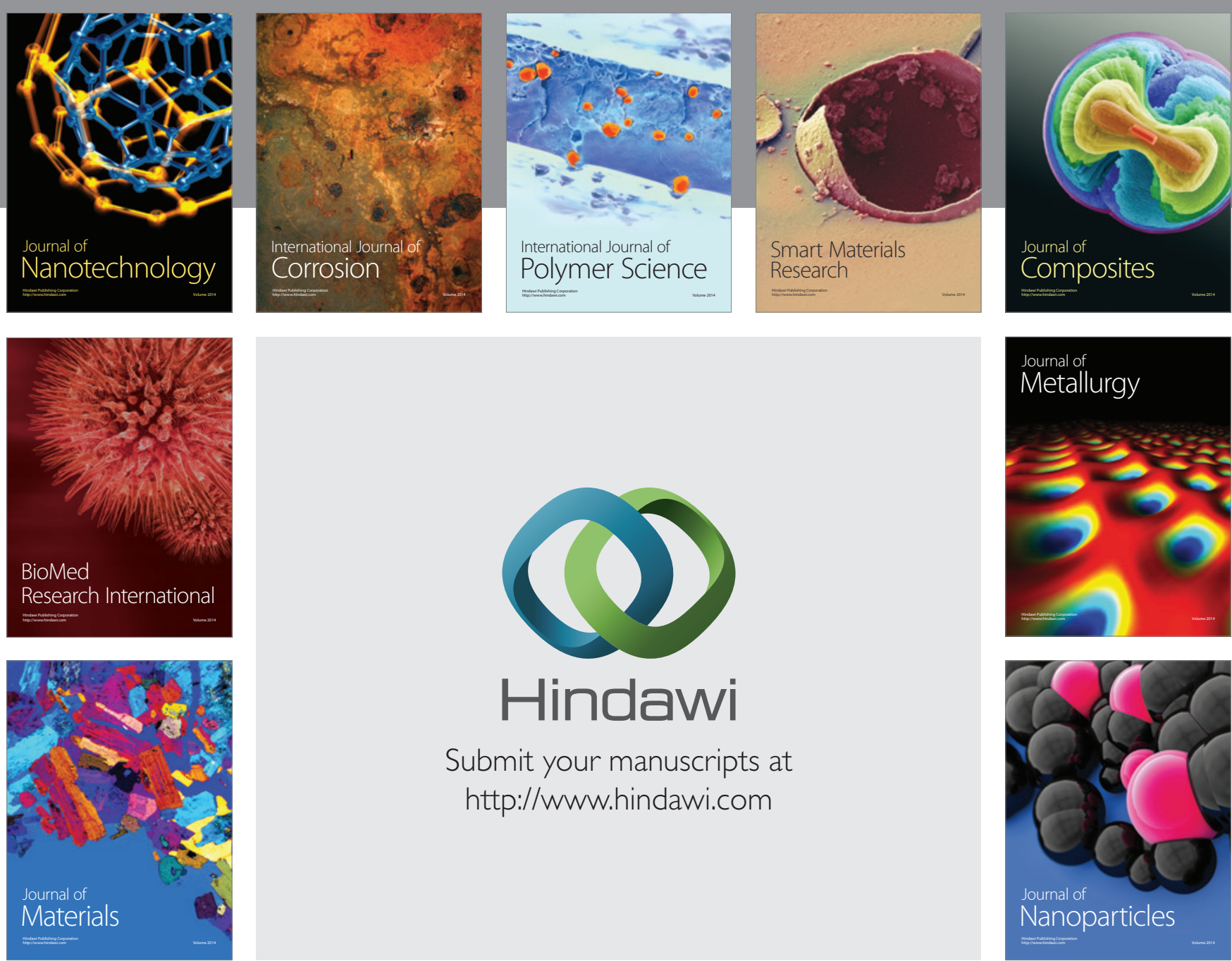

\section{Hindawi}

Submit your manuscripts at

http://www.hindawi.com

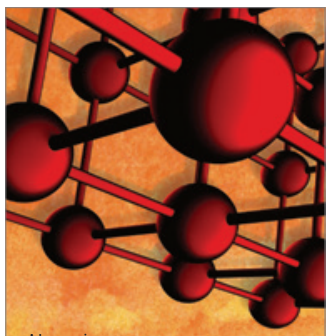

Materials Science and Engineering
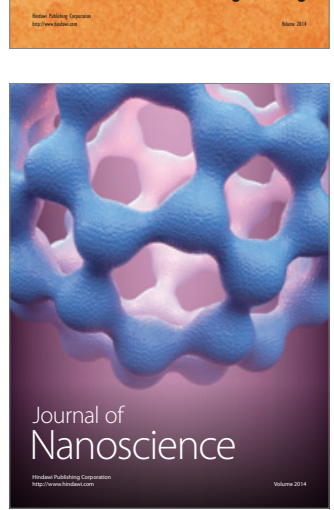
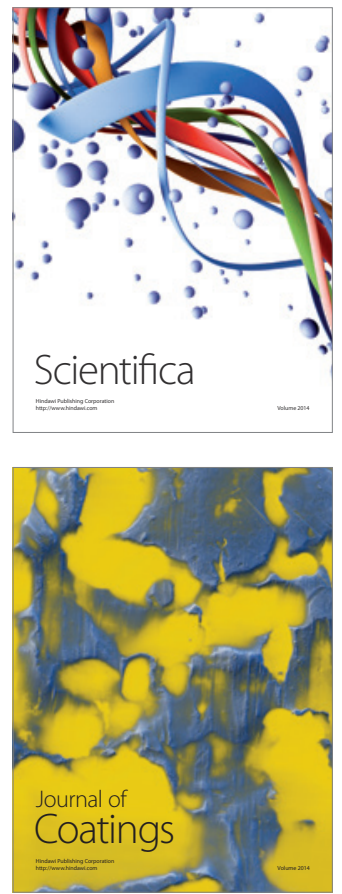
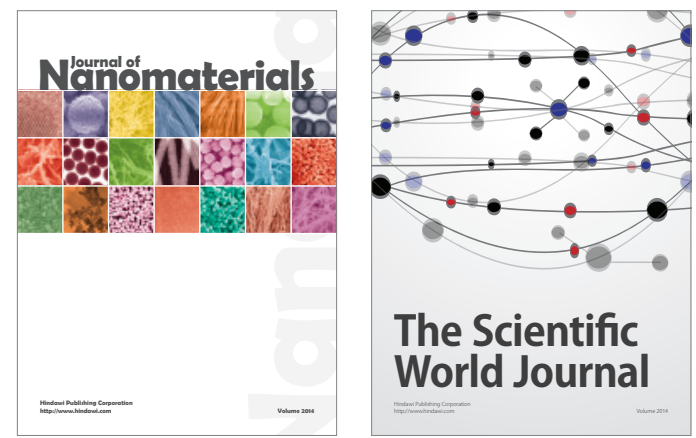

The Scientific World Journal
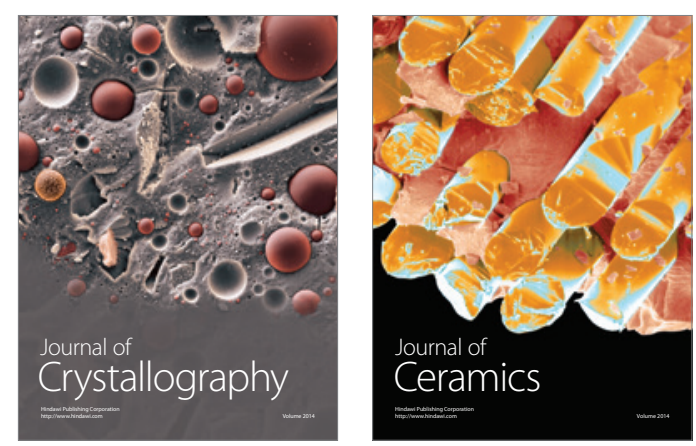
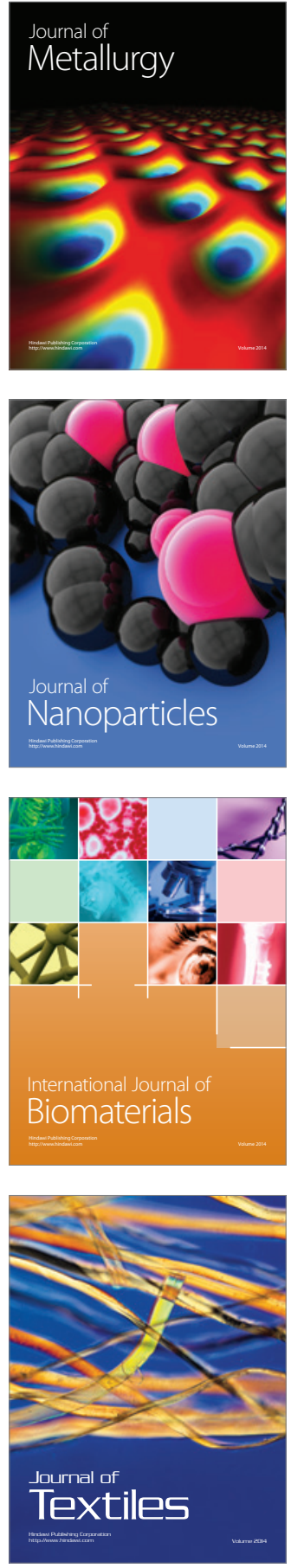